\title{
Virulence, Host-Selective Toxin Production, and Development of Three Cochliobolus Phytopathogens Lacking the Sfp-Type 4'-Phosphopantetheinyl Transferase Ppt1
}

\author{
Nur Ain Izzati Mohd Zainudin, ${ }^{1,2}$ Bradford Condon, ${ }^{1}$ Lieselotte De Bruyne, ${ }^{3}$ Christof Van Poucke, ${ }^{4}$ \\ Qing $\mathrm{Bi}^{1}{ }^{1}$ Wei Li, ${ }^{1,5}$ Monica Höfte, ${ }^{3}$ and B. Gillian Turgeon ${ }^{1}$ \\ ${ }^{1}$ Section of Plant Pathology \& Plant-Microbe Biology, School of Integrative Plant Science, Cornell University, Ithaca, NY 14853, \\ U.S.A.; ${ }^{2}$ Department of Biology, Faculty of Science, Universiti Putra Malaysia, 43400 Serdang, Selangor, Malaysia; \\ ${ }^{3}$ Department of Crop Protection, Laboratory of Phytopathology, Faculty of Bioscience Engineering, Ghent University, Ghent, \\ Belgium; ${ }^{4}$ Department of Bioanalysis, Laboratory of Food Analysis, Faculty of Pharmaceutical Sciences, Ghent University; and \\ ${ }^{5}$ Institute of Plant Protection, Jiangsu Academy of Agricultural Sciences, Nanjing, Jiangsu 210014, P.R. China
}

Submitted 30 March 2015. Accepted 26 May 2015.

\begin{abstract}
The Sfp-type 4'-phosphopantetheinyl transferase Ppt1 is required for activation of nonribosomal peptide synthetases, including $\alpha$-aminoadipate reductase (AAR) for lysine biosynthesis and polyketide synthases, enzymes that biosynthesize peptide and polyketide secondary metabolites, respectively. Deletion of the PPT1 gene, from the maize pathogen Cochliobolus heterostrophus and the rice pathogen Cochliobolus miyabeanus, yielded strains that were significantly reduced in virulence to their hosts. In addition, ppt 1 mutants of $C$. heterostrophus race $\mathrm{T}$ and Cochliobolus victoriae were unable to biosynthesize the hostselective toxins (HST) T-toxin and victorin, respectively, as judged by bioassays. Interestingly, ppt1 mutants of $C$. miyabeanus were shown to produce tenfold higher levels of the sesterterpene-type non-HST ophiobolin A, as compared with the wild-type strain. The ppt1 strains of all species were also reduced in tolerance to oxidative stress and iron depletion; both phenotypes are associated with inability to produce extracellular siderophores biosynthesized by the nonribosomal peptide synthetase Nps6. Colony surfaces were hydrophilic, a trait previously associated with absence of $C$. heterostrophus Nps4. Mutants were decreased in asexual sporulation and $C$. heterostrophus strains were female-sterile in sexual crosses; the latter phenotype was observed previously with mutants lacking Nps2, which produces an intracellular siderophore. As expected, mutants were albino, since they cannot produce the polyketide melanin and were auxotrophic for lysine because they lack an AAR.
\end{abstract}

Fungi produce secondary metabolites that are biosynthesized by polyketide synthase (PKS) and nonribosomal peptide synthetase (NRPS) megaenzymes activated by $4^{\prime}$-phosphopantetheinylation at conserved serine residues catalyzed by $4^{\prime}$-phosphopantetheinyl transferases (Pptases) (Allen et al. 2011; Crawford et al. 2008; Huang et al. 2006; Lambalot et al. 1996). Pptases belong to one of three families: i) halo-acyl carrier

Corresponding author: N. A. I. Mohd Zainudin; E-mail: ainizzati@upm.edu.my

*The $\boldsymbol{e}$-Xtra logo stands for "electronic extra" and indicates that four supplementary figures and three supplementary tables are published online.

() 2015 The American Phytopathological Society protein synthases, i) surfactin phosphopantetheinyl transferases (Sfp-type Pptases), or i) type I integrated Pptases. The prototype Pptase is the Sfp-type of Bacillus subtilis, which is vital for biosynthesis of the lipopeptide antibiotic surfactin (Copp and Neilan 2006; Quadri et al. 1998).

Filamentous fungal Sfp-type Pptase-encoding genes were identified and characterized first in Aspergillus nidulans (Oberegger et al. 2003) and have been described subsequently in fungal plant pathogens, such as the hemibiotrophs Colletotrichum graminicola, Magnaporthe oryzae (Horbach et al. 2009), and Cochliobolus sativus (Leng and Zhong 2012) and the necrotroph Fusarium fujikuroi (Wiemann et al. 2012) as well as in the biocontrol fungus Trichoderma virens (Velázquez-Robledo et al. 2011). Functional analysis of this type of Pptase in fungi has shown the enzyme to be required for biosynthesis of polyketide and nonribosomal peptides as well as for lysine biosynthesis.

Because NRPS and PKS require Pptases for biosynthesis of secondary metabolites involved in virulence to hosts, manipulation of PPT1 genes is a good first approach to determine if one or more of the suite of PKS- or NRPS-encoding genes in fungal genomes is a virulence determinant, since all are rendered nonfunctional at once. For example, pptl mutants of the corn anthracnose pathogen Colletotrichum graminicola are reduced in virulence and are unable to synthesize siderophores, melanin, and lysine (Horbach et al. 2009). Mutants are also sensitive to oxidative stress and are reduced in asexual sporulation. Likewise, ppt1 mutants of the rice blast fungus Magnaporthe oryzae are incapable of penetration because they lack melanin, and therefore, are unable to cause the disease (Horbach et al. 2009). Relevant to the current work, ppt 1 mutants of the cereal pathogen C. sativus have been shown to cause less disease on barley cv. Bowman compared with wild type (WT) and are reduced in ability to manage oxidative stress, although the causal metabolites linked to these phenotypes were not identified (Leng and Zhong 2012). Pptase1 of the necrotroph Fusarium fujikuroi is known to be involved in production of metabolites such as pigments (bikaverins and fusarubins) and mycotoxins (fusarins) (Wiemann et al. 2012). Lysine is essential for pathogenicity on rice roots; however, no additional metabolites beyond iron-gathering siderophores were identified as necessary for virulence.

Although the role of Ppt 1 in virulence has been documented for the hemibiotroph $C$. sativus, it has not been examined in 
necrotrophic Cochliobolus species, which are known to produce secondary metabolite host-selective toxins (HST) that play a primary role in disease development during infection. Here, we assessed whether ppt 1 mutants of a race $\mathrm{T}$ strain of the maize pathogen $C$. heterostrophus still produce T-toxin (Baker et al. 2006; Yang et al. 1996) and found that they do not. In addition, we assessed the effect of deletion of $P P T 1$ on victorin production by $C$. victoriae by bioassay with leaves of susceptible oats and found that mutant phenotypes were the same as on resistant leaves, suggesting they lack the HST victorin (Macko et al. 1985; Wolpert et al. 2002). We also examined the rice pathogen C. miyabeanus, for which no HST is known but which produces several secondary metabolites that act as nonspecific phytotoxins, including the terpenoid ophiobolin A (Ahn et al. 2005). Mutants of C. miyabeanus showed a tenfold increase in ophiobolin A when compared with the WT strain in liquid culture. The absence of PPT1 appears to have upset homeostasis of other metabolites not dependent on it for biosynthesis.

\section{RESULTS}

\section{Identification of the Sfp-type Ppt1 proteins}

in $C$. heterostrophus, $C$. victoriae, and $C$. miyabeanus and phylogenetic relationship to known Ppt proteins.

A single Ppt protein candidate was identified in C. heterostrophus C5 $\left(\mathrm{E}\right.$ value $=3.76 \times \mathrm{e}^{-28}$, Joint Genome Institute (JGI) protein ID 96896) when queried with the Aspergillus nidulans NpgA protein sequence (GenBank AF198117; JGI protein ID 4132). When the strain $\mathrm{C} 5$ protein was used to query the $C$. heterostrophus $\mathrm{C} 4, C$. victoriae $\mathrm{FI} 3$, and C. miyabeanus WK1C genomes, single orthologs were identified in each (C4, JGI protein ID 23829; FI3, JGI protein 110360; and WK1C, JGI protein ID 88023).

Phylogenetic analysis indicated that the ChPpt1, CvPpt1, and CmPpt1 proteins fall in a well-supported group of dothideomycete Ppt1 homologs with 89\% support (Supplementary Fig. S1). This group is sister to the eurotiomycete group that includes $A$. nidulans NpgA. Phylogenetic analysis showed that candidate Cochliobolus Ppt 1 proteins are highly conserved (100\% bootstrap support) in all species examined, except for $C$. lunatus (84\%). This is expected, since, among Cochliobolus species, this is the only one included with a Curvularia rather than a Bipolaris asexual stage (Condon et al. 2014b).

\section{Polymerase chain reaction $(\mathrm{PCR})$ verification of PPT1 deletion.}

Loss of $P P T 1$ and correct insertion of the selectable marker into the $5^{\prime}$ and $3^{\prime}$ regions flanking the PPT1 target gene in C. heterostrophus, C. victoriae, and C. miyabeanus were verified by PCR, using diagnostic primer pairs (Supplementary Fig. S2), as described below and by Inderbitzin et al. (2010). Deletion strains of each species verified as a ppt1 mutant (Chppt1-1D, Chppt1-2A, Chppt1-2D, Cmppt1-1, Cmppt1-4, Cmppt1-8, Cvppt1-2, Cvppt1-3, Cvppt1-4, and Cvppt1-7) were used for subsequent assays.

\section{Growth and lysine requirement.}

Growth of all pptl mutants was reduced to 45 and $50.5 \%$, respectively, of that of the corresponding WT strains $(P<0.05)$ when strains were grown on complete medium with $1 \%$ xylose (CMX) (Fig. 1A, C. victoriae data not shown). Growth phenotypes of all mutants on minimal medium (MM) with or without supplemental lysine $(100 \mu \mathrm{M})$ confirmed that the strains are auxotrophic for lysine (Fig. 1B and C).

\section{Ppt1 is necessary for full virulence}

of $C$. heterostrophus and $C$. miyabeanus on their hosts.

To examine virulence of $C$. heterostrophus pptl mutants, which are auxotrophic for lysine, we initially inoculated plants with spores in $0.02 \%$ Tween 20 with and without supplemental lysine. Length of disease lesions of all strains increased when lysine was included, indicating that supplemental lysine can be
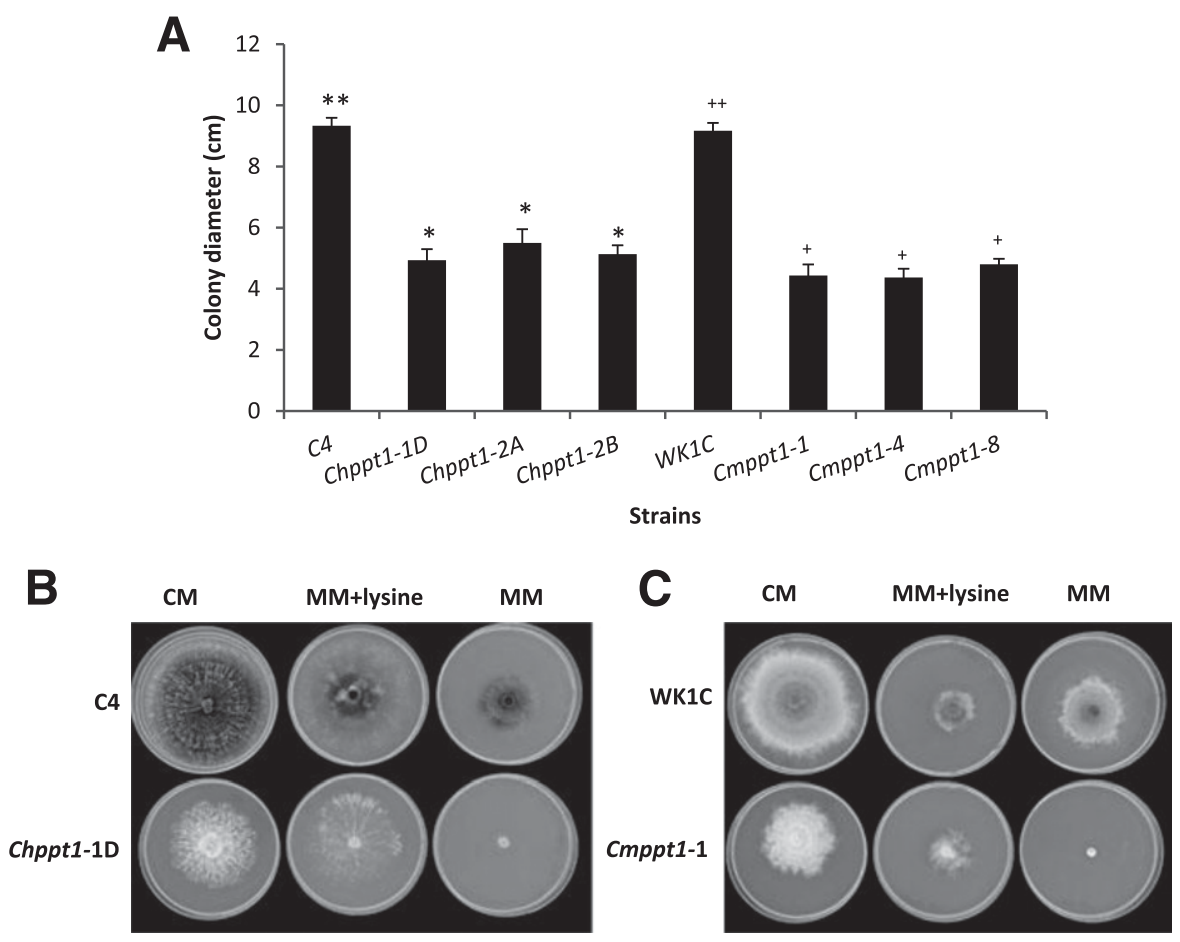

Fig. 1. Growth of wild type and ppt 1 mutants with and without supplemental lysine. A, ppt1 mutants are impacted in growth on complete medium with $1 \%$ xylose. $C h=$ Cochliobolus heterostrophus, $C m=C$. miyabeanus. Mean and standard deviation (error bars) are shown. Different symbols indicate significant differences at $P<0.05$ when analyzed using one-way analysis of variance, and all ppt 1 mutants were compared with their corresponding wild type. B, C. heterostrophus and $\mathbf{C}, C$. miyabeanus ppt 1 mutants are albino and require supplemental lysine for growth on minimal medium. 
accessed by the mutants (Fig. 2A and B). At 5 days postinoculation (dpi) on $\mathrm{N}$-cytoplasm maize, leaves inoculated with WT $C$. heterostrophus had extensive necrotic lesions while all pptl mutants produced fewer and smaller lesions that were comparable to those of the nps 2 nps 6 double siderophore mutant $(1.82 \pm 0.69 \mathrm{~mm})$ included as a reduced virulence control (Condon et al. 2014a). Lengths of lesions caused by Chppt1-1D, Chppt1-2A, and Chppt1-2B mutants were significantly different at $P<0.05(1.62 \pm 0.68,1.54 \pm 0.98$, and $1.54 \pm 0.75 \mathrm{~mm}$, respectively) compared with WT $(4.10 \pm$ $1.42 \mathrm{~mm}$ ), when individual lesions were measured (Fig. 2D). This confirms that $C$. heterostrophus secondary metabolites dependent on Ppt1 are important for full virulence to the host. Our control was to use the nps2nps6 double mutant lacking ability to produce both intra and extracellular siderophores but with a WT PPT1 gene. Because reduction in virulence was comparable to reduction caused by the siderophore double mutant, we conclude that these metabolites are likely absent in the ppt 1 mutant, as expected, and that it is unlikely that additional metabolites that require a NRPS or PKS for biosynthesis have a significant impact on virulence.

Because C. miyabeanus ppt 1 mutants make no or very few conidia (discussed below), virulence was tested by inoculating a mycelial suspension of the mutants with supplemental lysine into rice leaves. Inoculation with a mixture of WT mycelia and spores was used as control. At $10 \mathrm{dpi}$, WT had developed large dark-brown necrotic areas surrounded by chlorotic halos (Fig. 2C). Cmppt1 mutants caused much less damage and appeared as light-brown patches without obvious chlorosis, in most cases. Average diseased area lengths of the Cmppt1-1, Cmppt1-4, and Cmppt1-8 mutants were $3.66 \pm 0.79$, $3.66 \pm 1.02$, and $3.77 \pm 0.76 \mathrm{~mm}$, respectively, compared with WT, which was $6.10 \pm 1.41 \mathrm{~mm}$ (Fig. 2D). Thus, like the better-studied $C$. heterostrophus, $C$. miyabeanus secondary metabolites dependent on Ppt 1 are important for full virulence to the host.

\section{Bioassays indicate that PPT1 deletion eliminates production of the HST T-toxin} by $C$. heterostrophus race $\mathrm{T}$ and victorin by $C$. victoriae.

T-toxin, a HST produced by race T of C. heterostrophus, requires two PKS (PKS1 and PKS2) (Baker et al. 2006) for its biosynthesis. All three independent race $\mathrm{T}$ ppt 1 mutants were unable to produce T-toxin, as shown in a standard microbial assay (Ciuffetti et al. 1992). The positive and negative control strains, C4 (race T) and C5 (race O), produced and failed to
A

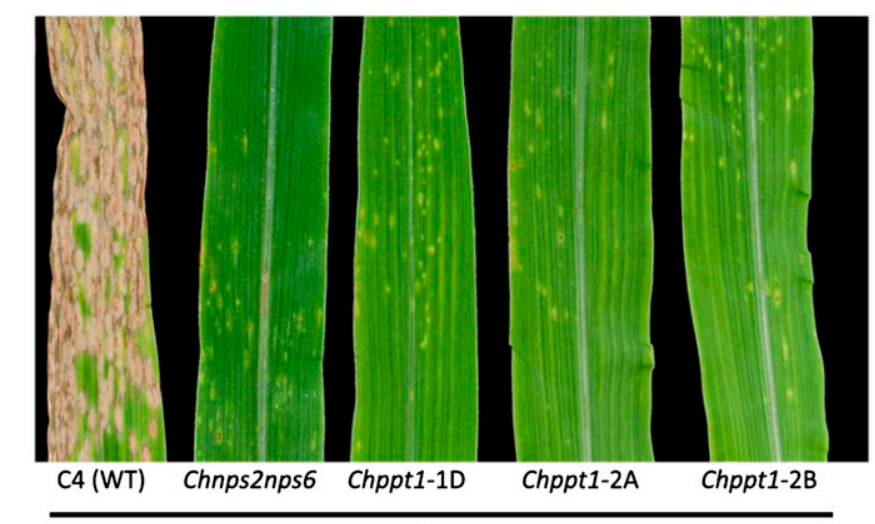

C
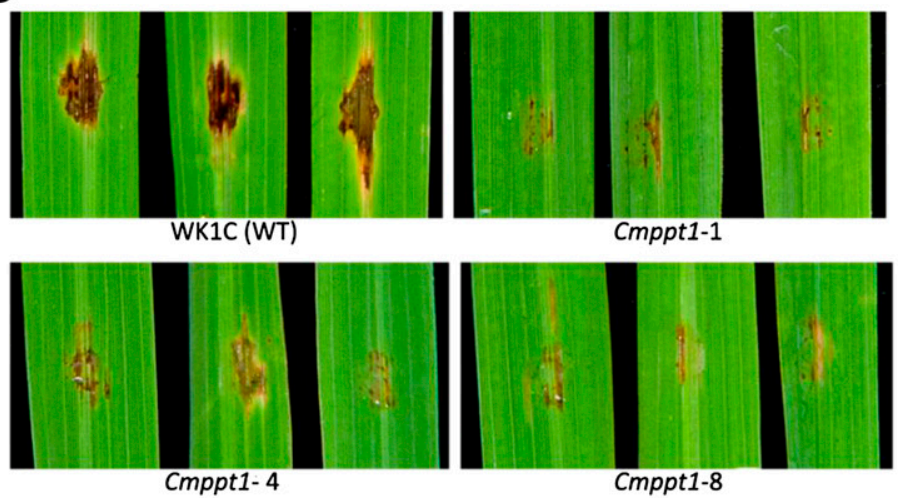

lysine
B

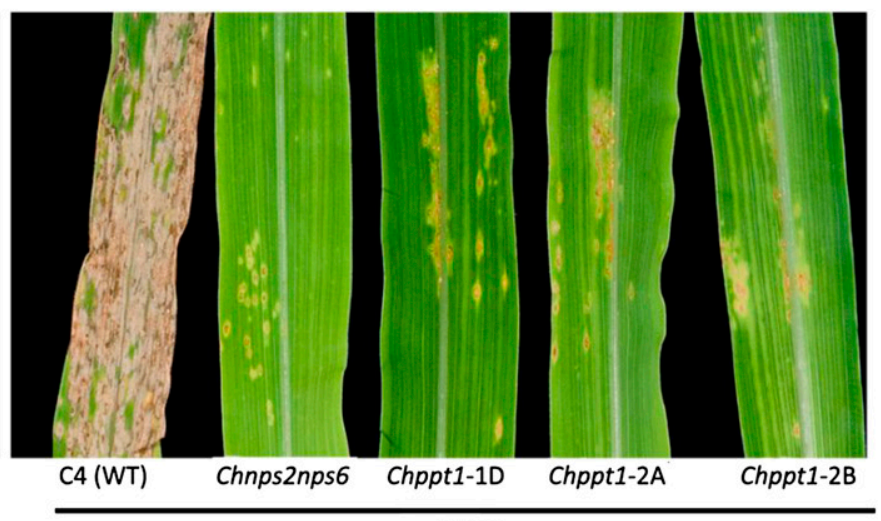

D

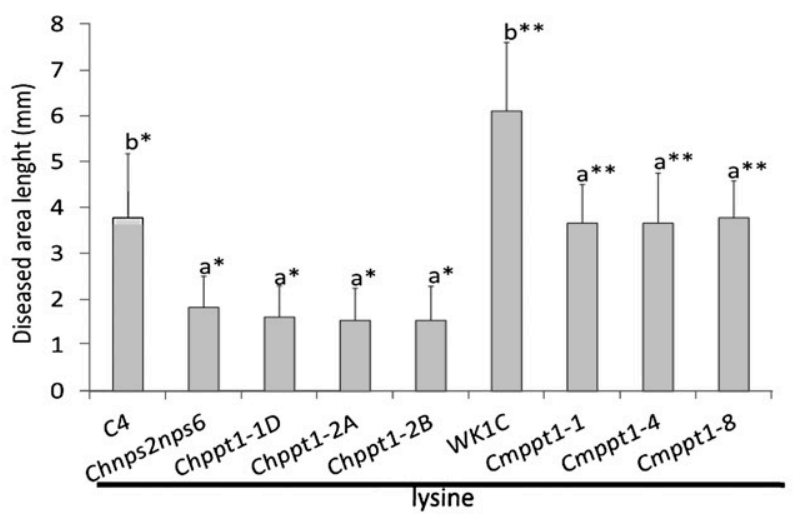

Fig. 2. Chppt1 and Cmppt1 mutants show reduced virulence to maize and rice, respectively. A, Virulence of Chppt 1 mutants and wild type (WT) on maize variety W64A-N. Leaves were inoculated with WT race T strain C4, Chppt1-1D, Chppt1-2A, Chppt1-2B, and a Chnps2nps6 mutant, which lacks ability to produce intra- and extra cellular siderophores and is a reduced virulence control (Condon et al. 2014a). Chppt1 mutant lesion length was reduced compared with WT, but mutants are still weakly pathogenic. Conidia without supplemental lysine were sprayed on leaves. B. Leaves were sprayed with C. heterostrophus as in A, but the conidial suspension was supplemented with $50 \mu \mathrm{g}$ of lysine per milliliter. Note that lengths of lesions caused by the mutants increased indicating that lysine was accessible and improved the in planta growth of mutants. C, Virulence of Cmppt1 mutants and WT on rice (variety Nipponbare). Amount of diseased tissue is much greater when WT mycelial fragments were used for inoculation than when those of Cmppt Imutants were used. D, Lesion lengths of the Southern corn leaf blight symptoms caused by Cochliobolus heterostrophus on maize leaves shown in B at 5 days postinoculation (dpi) and of brown spot disease caused by $C$. miyabeanus on rice shown in $\mathrm{C}$ at $10 \mathrm{dpi}$. The mean and standard deviation (error bars) are shown. Different letters and symbols indicate significant differences at $P<0.05$ when analyzed using one-way analysis of variance, and all ppt 1 mutants were compared with their corresponding WT. 


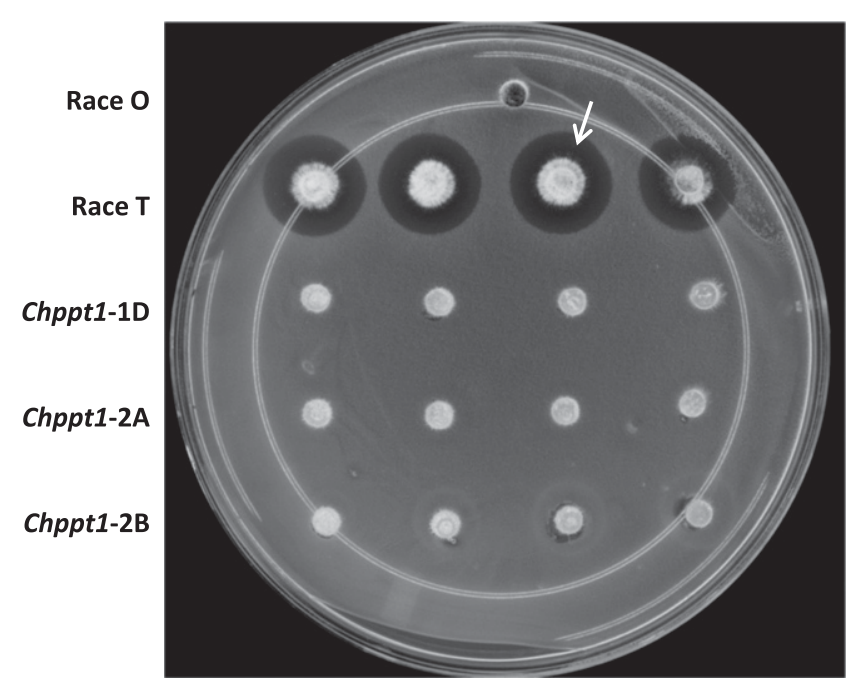

Fig. 3. Cochliobolus heterostrophus ppt1 mutants are unable to synthesis T-toxin. Microbial assay plate for T-toxin production (Ciuffetti et al. 1992). Note that the positive wild-type race $\mathrm{T}$ control plugs are surrounded by dark halos (white arrow), which indicate killing of Escherichia coli cells carrying the maize protein Urf13, the T-toxin target. The race $\mathrm{O}$ negative control plug and plugs of pptl mutants fail to make T-toxin. produce T-toxin, respectively (Fig. 3). Genes for victorin production, a host-selective pentapeptide toxin produced by $C$. victoriae, have not been identified but are predicted to include a NPS or NPS:PKS hybrid gene (Condon et al. 2013). When leaves of susceptible and resistant oats were tested in filtrates of C. victoriae WT and ppt1 mutants, susceptible leaves of WT wilted and fell over within $24 \mathrm{~h}$ and by $48 \mathrm{~h}$ were shriveled, whereas those of the pptl mutants remained upright, suggesting absence of or reduced production of victorin (Fig. 4). Resistant leaves remained upright in filtrate from both WT and mutants.

\section{PPT1 deletion induces production of the nonselective sesterterpene toxin ophiobolin A by $C$. miyabeanus.}

To investigate whether PPT1 deletion affects biosynthesis of other types of secondary metabolites such as terpenoids, production of ophiobolin A, a sesterterpene type non-HST, was quantified in liquid culture extracts, using liquid chromatographytandem mass spectrometry (LC-MS/MS). The pptl mutant (strain Cmppt1-1) produced 10.6 times more ophiobolin A per gram of mycelium compared with WT strain WK1C $(P<0.05)$ (Fig. 5). This indicates that impairing biosynthesis of one or more polyketides, nonribosomal peptides, or both prompted overproduction of this metabolite.

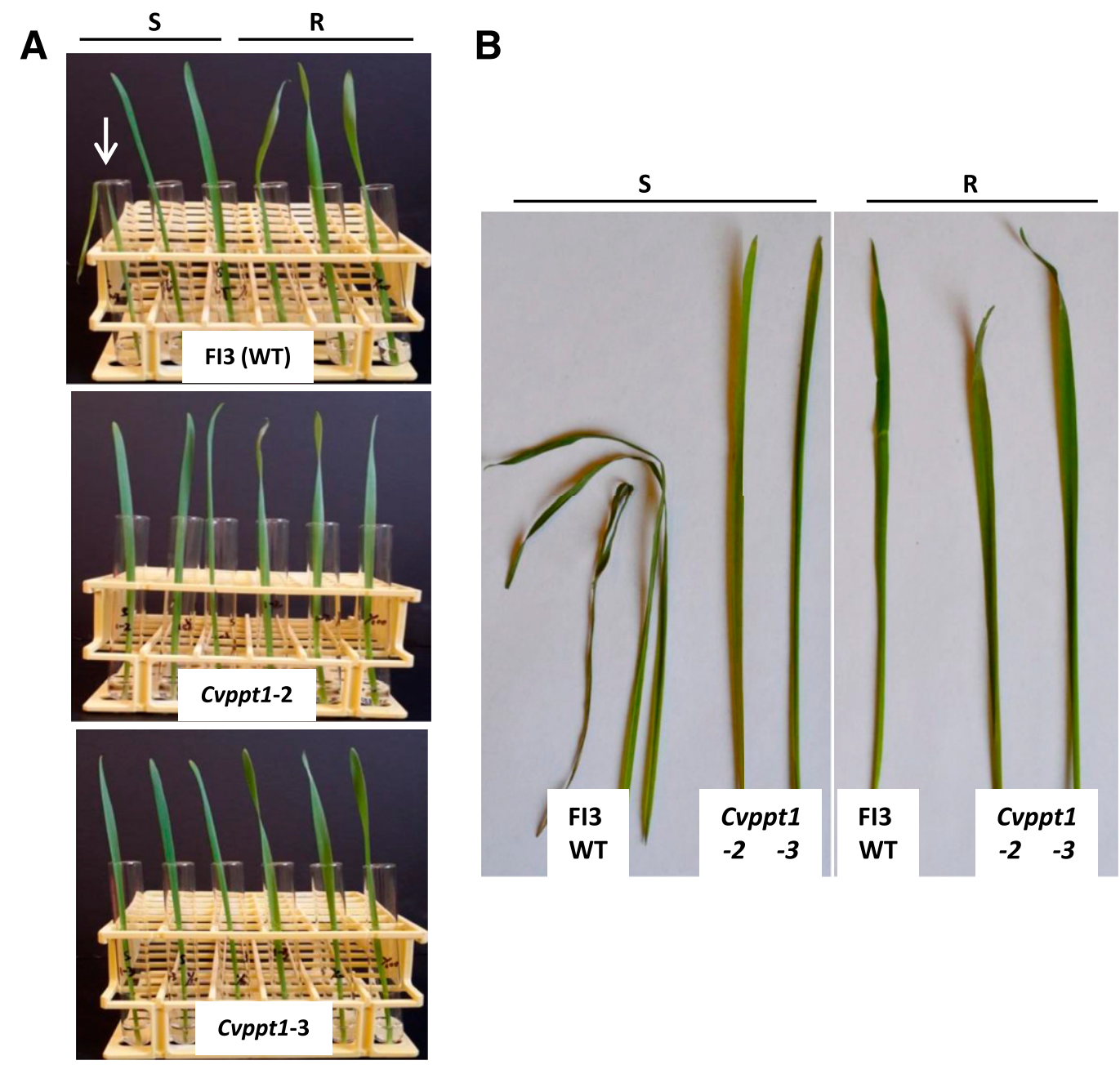

Fig. 4. Cochliobolus victoriae victorin assay. A, Wild-type (WT) culture filtrates (top), mutant ppt1-2 culture filtrates (middle), and mutant ppt1-3 culture filtrates (bottom), showing, from left, three susceptible and three resistant leaves in undiluted, 1:10, 1:100 diluted filtrate, respectively. Note only the susceptible leaf in WT undiluted filtrate is wilted. The image was taken 1 day after setting up the assay. B, Leaves in undiluted filtrates assayed at 2 days. Cultures as in A. S = susceptible leaves, $\mathrm{R}=$ resistant leaves. Note only susceptible leaves (S) from WT undiluted filtrate are shriveled or wilted. The image was taken 2 days after setting up the assay. 


\section{PPT1 deletion affects resistance}

\section{to oxidative and low-iron stress.}

Chppt1, Cmppt1 (Fig. 6A, Supplementary Fig. S3A), and Cvppt1 (Supplementary Fig. S4) mutants are sensitive to oxidative stress mediated by $\mathrm{H}_{2} \mathrm{O}_{2}$ and to low-iron stress. Growth of Chppt1 strains was severely inhibited on $2 \mathrm{mM} \mathrm{H}_{2} \mathrm{O}_{2}$ and there was no growth on $4 \mathrm{mM} \mathrm{H}_{2} \mathrm{O}_{2}$ (Fig. 6A), while WT strain $\mathrm{C} 4$ could still grow on $8 \mathrm{mM} \mathrm{H}_{2} \mathrm{O}_{2}$. Cmppt1 mutants were less inhibited on $4 \mathrm{mM}$ but showed no growth on $8 \mathrm{mM} \mathrm{H}_{2} \mathrm{O}_{2}$, a concentration at which WT was still able to grow (Fig. 6B).

C. heterostrophus ppt1 mutants were completely inhibited when the iron chelator 2DP was added to plates at a concentration of $100 \mu \mathrm{M}$, whereas WT was still able to grow at $200 \mu \mathrm{M}$ (Fig. 6C). Cmppt1 mutants were more sensitive and stopped growing at $50 \mu \mathrm{M}$, in contrast to WT $C$. miyabeanus, which still had some growth on $100 \mu \mathrm{M}$ but no growth on $200 \mu \mathrm{M}$ (Fig. 6D). Previously, we demonstrated that $C$. heterostrophus and $C$. miyabeanus mutants lacking the NPS6 gene, responsible for production of extracellular siderophores, are hypersensitive to oxidative stress and to low-iron stress (Lee et al. 2005; Oide et al. 2006). As the ppt1 mutant phenotype mirrors that of $n p s 6$ mutants, we conclude that this phenotype is largely, if not entirely, attributable to lack of NPS6.

\section{PPT1 deletion affects production of melanin and leads to hydrophilic colony surfaces.}

All pptl mutants of the three species are albino, which suggests that melanin, which requires $C$. heterostrophus PKS18 (JGI ID 82412) for biosynthesis (Wu et al. 2012), is not made (Fig. 1B and C). C. miyabeanus and C. victoriae carry single orthologs of $C$. heterostrophus PKS18 (JGI ID 83967 and 86149, respectively) (Condon et al. 2013).

Loss of $P P T 1$ in $C$. heterostrophus and C. miyabeanus resulted in hydrophilic colony surfaces (Fig. 7A and B) in contrast to corresponding WT strains. The latter retained droplets of water indefinitely, while droplets of water on ppt1 mutant colony surfaces soaked in with time. Chpptl mutants did so within 5 min, while Cmppt1 mutants took about $2 \mathrm{~h}$.

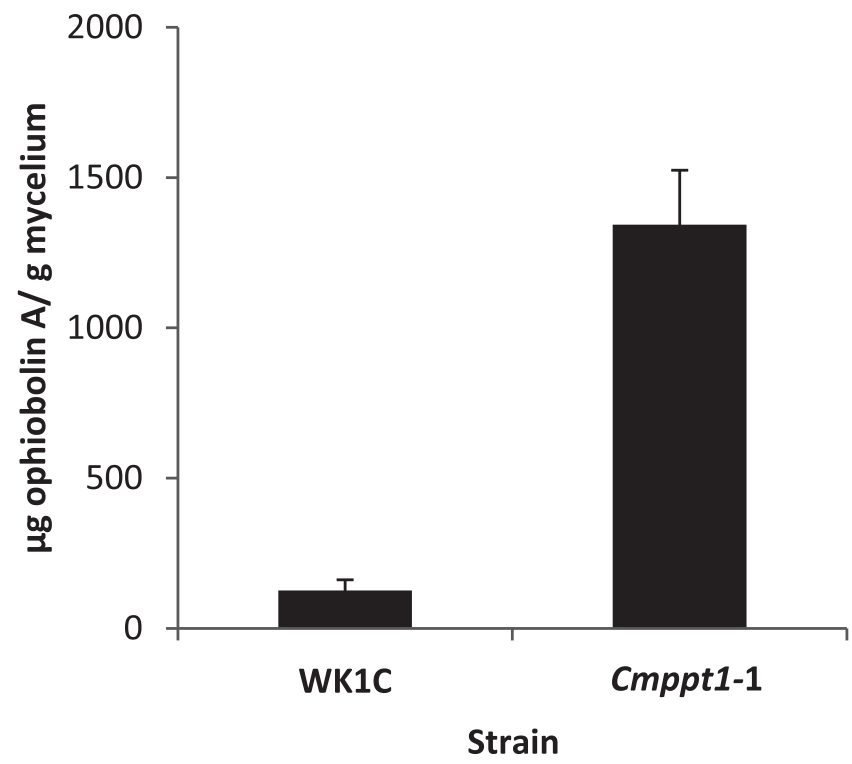

Fig. 5. Ophiobolin A production is increased in Cochliobolus miyabeanus ppt1 mutants. Amount of ophiobolin A produced by wild type (WT) and Cmppt1-1 as quantified by liquid chromatography-tandem mass spectrometry, in micrograms per gram of mycelium dry weight. Cmppt1 mutants produced 10.6 times more ophiobolin A compared with WT strain WK1C $(P<0.05$, student $t$ test $)$. The data show the mean of three biological replicates, error bars represent the standard error.

\section{C. heterostrophus ppt1 mutants are female-sterile.}

To determine whether loss of PPT1 influences reproductive development, we crossed albino Chppt1 mutants (MAT1-2) to pigmented WT strain C5 (MAT1-1). The progenitor of the mutants, pigmented strain $\mathrm{C} 4$ was also crossed to inbred albino WT strain CB7 (MAT1-2) as a control. Control crosses produced both pigmented and albino pseudothecia, indicating both strains are hermaphroditic (Fig. 8A). Crosses of albino Chppt1 mutants to WT C5 produced pigmented pseudothecia only (Fig. 8A and B), indicating that Chpptl mutants are female-sterile, since pseudothecium color is determined by the strain acting as the female. The total number of pigmented pseudothecia produced in the Chpptl crosses was significantly less than in the control crosses (Fig. 8B). The number of asci and the number of mature ascospores per ascus, however, were not significantly different when contents of mutant and WT crosses were compared (not shown).

C. miyabeanus WT strain WK1C was previously reported as a fertile strain (Chang 1980). We attempted crosses of WT WK1C and all Cmppt1 mutants (in the WK1C, MAT1-2 genetic background) to MAT1-1 C. miyabeanus WT strains, Texas 2, and NI271Leo but none was able to mate; thus, we could not assess fertility in C. miyabeanus.

All known C. victoriae strains are MAT1-2 and female-sterile (Christiansen et al. 1998); therefore, we could not examine the effect of loss of PPT1 on sexual reproduction.

\section{C. heterostrophus, $C$. victoriae, and C. miyabeanus ppt1 mutants are reduced in asexual sporulation.}

Chppt1 mutants grown under constant light, in 12-h light and12-h dark, and in constant dark, all produced significantly fewer conidia than WT (Fig. 8C). Cmppt1 and Cvppt1 mutants were incapable of, or drastically reduced in, producing conidia on CMX after 2 weeks of incubation, in contrast to WT strains. Thus, Ppt1 appears to be required for asexual development of $C$. miyabeanus and C. victoriae and for production of WT numbers of asexual spores of $C$. heterostrophus.

\section{DISCUSSION}

One goal of this study was to examine the effect of loss of PPT1 on virulence in two host-specific Cochliobolus necrotrophs, C. heterostrophus (host corn) and C. miyabeanus (host rice). A second goal was to determine if loss of Ppt1 affects production of the HST T-toxin and victorin.

C. heterostrophus exists as two races, $\mathrm{T}$ and $\mathrm{O}$; both are pathogenic. Race $\mathrm{T}$, however, is highly virulent on maize carrying T-cytoplasm because $\mathrm{T}$-cytoplasm carries the $\mathrm{T}$-toxin target (the maize Urf-13 protein) (Baker et al. 2006; Rhoads, Levings and Siedow 1995). Since we already know the effect of T-toxin on virulence, we tested instead for basic pathogenic ability of race T ppt 1 mutants on N-cytoplasm corn (Fig. 2), because it lacks the T-urf13 target. Symptoms attributable to T-toxin are irrelevant in this context. Furthermore, disease symptoms are easier to score on N-cytoplasm, as chlorosis due to toxin production does not impact lesion scoring in WT. C. heterostrophus ppt1-deletion mutants, indeed, showed reduced virulence to maize (Fig. 2). Both size and frequency of necrotic lesions were affected (Fig. 2A, B, and D). At 5 dpi, most of the leaf surface was necrotic, brown, and shriveled, when inoculated with WT spores. In contrast, leaves inoculated with the same number of pptl mutant spores produced many fewer lesions and these were smaller in size and less necrotic. These data indicate that polyketide or nonribosomal peptide secondary metabolites are involved in disease progression, since all of these types of metabolite should be absent in ppt 1 mutants. 

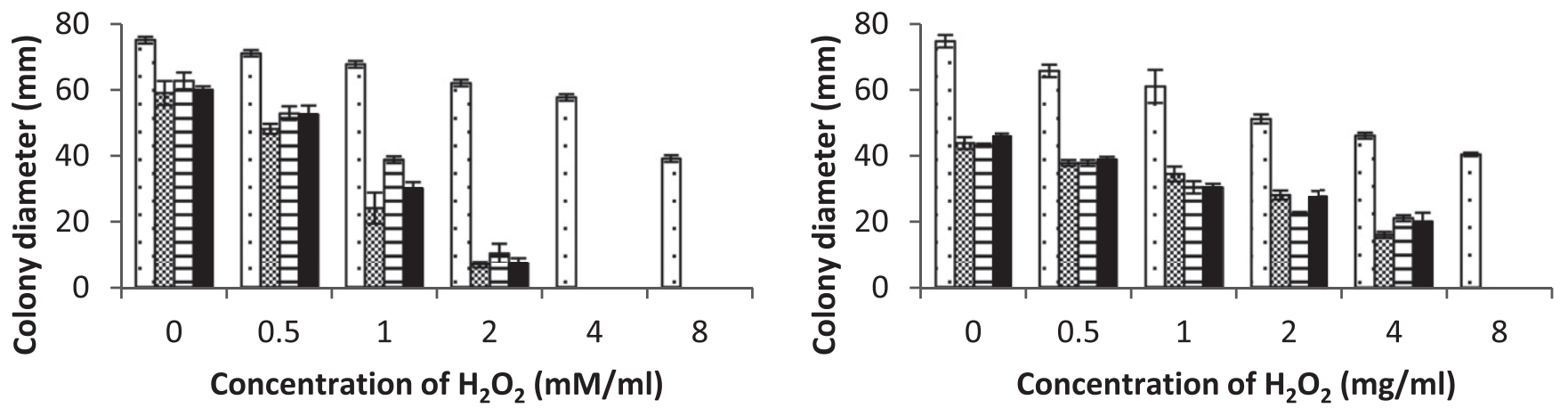

\section{C}

D

$\square$ C4 (WT) 圆Chppt1-2A 日Chppt1-2B —Chppt1-1D
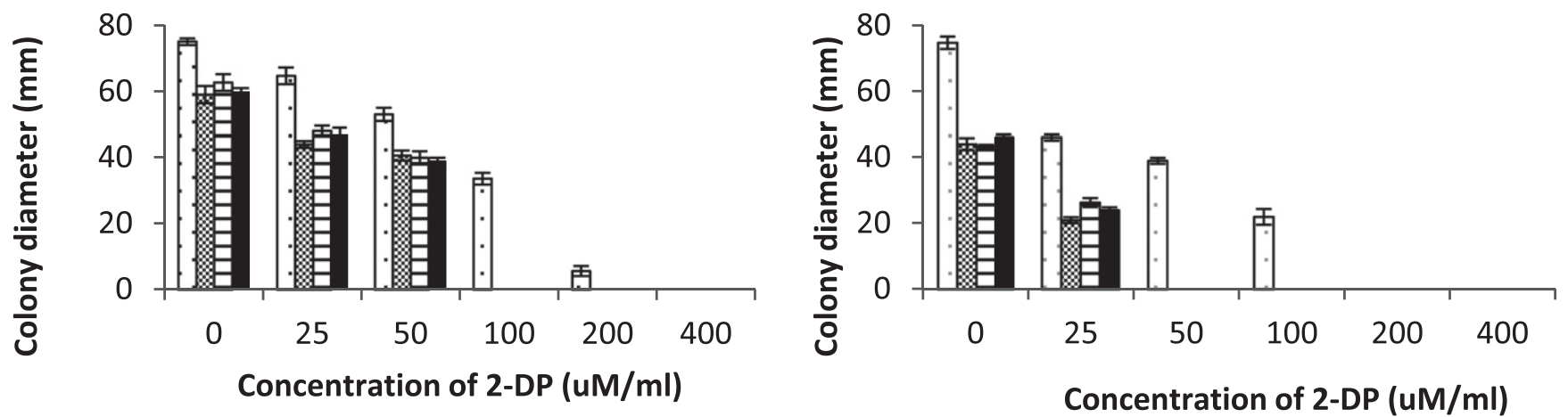

Fig. 6. Cochliobolus heterostrophus and C. miyabeanus ppt 1 mutants are sensitive to oxidative and low-iron stress. A, Growth of Chppt 1 strains was severely inhibited at $2.0 \mathrm{mM}$ and no growth occurred at $4.0 \mathrm{mM} \mathrm{H}_{2} \mathrm{O}_{2}$, while wild-type (WT) strain C4 was still able to grow on $8 \mathrm{mM} \mathrm{H}_{2} \mathrm{O}_{2}$. B, Cmppt1 mutant growth was less sensitive to $2.0 \mathrm{mM} \mathrm{H}_{2} \mathrm{O}_{2}$ than were Chppt1 mutants and the strains were still able to grow on $4.0 \mathrm{mM} \mathrm{H}_{2} \mathrm{O}_{2}$. However, like Chppt1 mutants, no growth occurred on $8.0 \mathrm{mM} \mathrm{H}_{2} \mathrm{O}_{2}$. Like $C$. heterostrophus WT, C. miyabeanus WT survived well at $8 \mathrm{mM} \mathrm{H}_{2} \mathrm{O}_{2}$. C, Growth of Chppt1 mutants was completely inhibited when the iron chelator 2-DP was added to plates at a concentration of $100 \mu \mathrm{M}$, whereas WT was still able to grow at $200 \mu \mathrm{M}$. D, Cmppt1 mutants were more sensitive than Chppt1 mutants, as no growth was seen on $50 \mu \mathrm{M}$ 2-DP and WT WK1C was unable to grow at all on 200 $\mu \mathrm{M} 2$-DP.
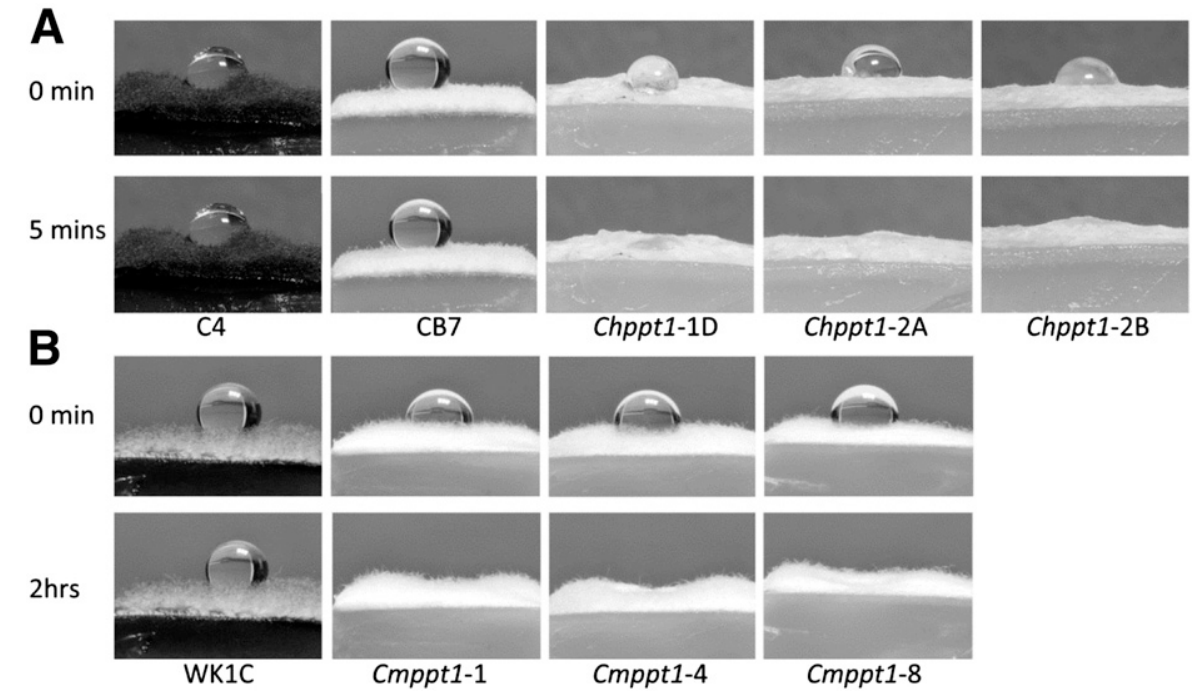

Fig. 7. Chppt1 and Cmppt1 mutants have hydrophilic colony surfaces. A, Wild-type (WT) strains C4 (WT pigmented) and CB7 (WT albino) colony surfaces are hydrophobic as evidenced by retention of water droplets, while droplets on Chppt 1 mutants disappeared within 5 minutes, indicating they are hydrophilic. B, Cmppt1 mutants are also hydrophilic, but droplets took $2 \mathrm{~h}$ to completely soak in. WT strain WK1C is hydrophobic and retained the droplet. 
For $C$. heterostrophus, the ppt1 mutant lesion sizes were approximately the same as those of nps2nps6 mutants (Fig. 2); thus, the pptl phenotype could be due entirely to lack of siderophores. Our previous data showed that, when each of the 14 genes encoding NRPS in the $C$. heterostrophus genome was deleted individually, the $n p s 6$ mutant was the only single gene mutant with an altered virulence phenotype (Oide et al. 2006). Additional work, however, revealed that when NPS2 (responsible for intracellular siderophore production) is deleted in a $n p s 6$ mutant background, the double nps $2 n p s 6$ mutant (lacking ability to produce both extra- and intracellular siderophores) is much more reduced in virulence than the single $n p s 6$ mutant that lacks only extracellular siderophores (Condon et al. 2014a). Thus, although we cannot definitively rule out the possibility that additional NRPS or PKS-produced secondary metabolites contribute to virulence, their role may be minor, as level of disease caused by ppt 1 mutants phenocopies that of nps2nps6 mutants on $\mathrm{N}$-cytoplasm corn.

For $C$. miyabeanus, inoculation with the pptl mutants also resulted in reduced virulence (Fig. 2C and D) compared with WT. Lesion length measurements indicated a statistically significant $(P<0.05)$ reduction in size compared with WT lesion

\section{A}

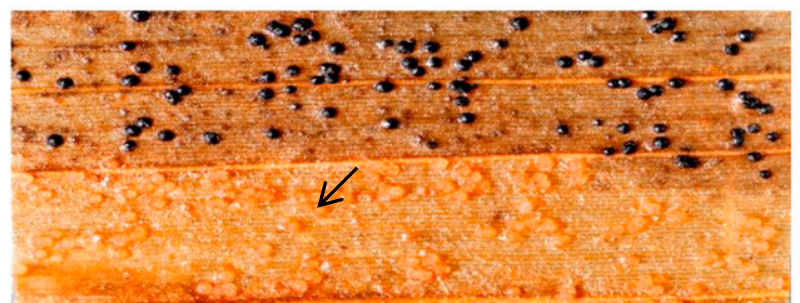

$\mathrm{C} 4 \times \mathrm{CB} 7$

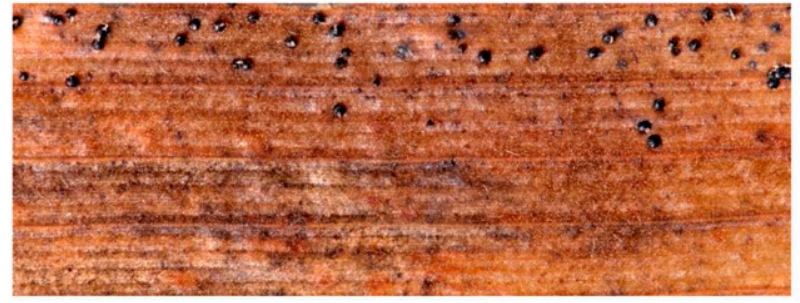

C5 x Chppt1-1D

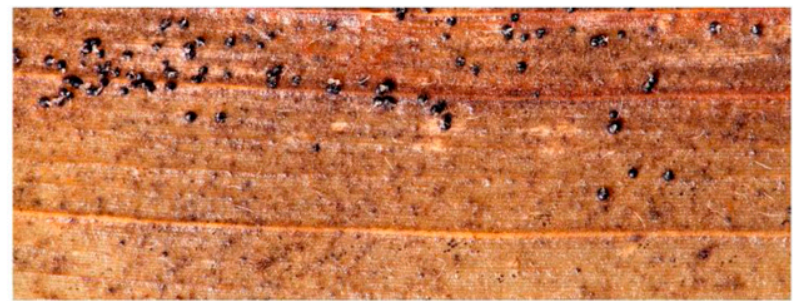

C5 x Chppt1-2A

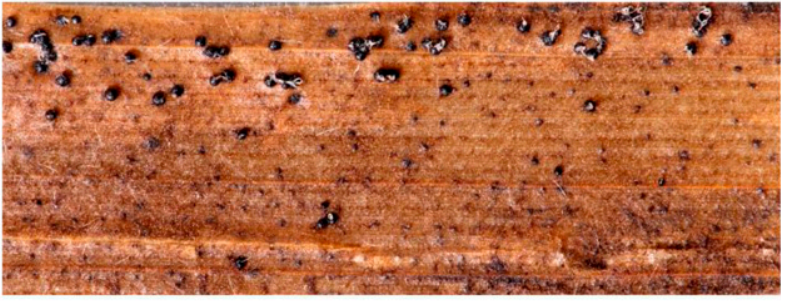

C5 $\times$ Chppt1-2B
B

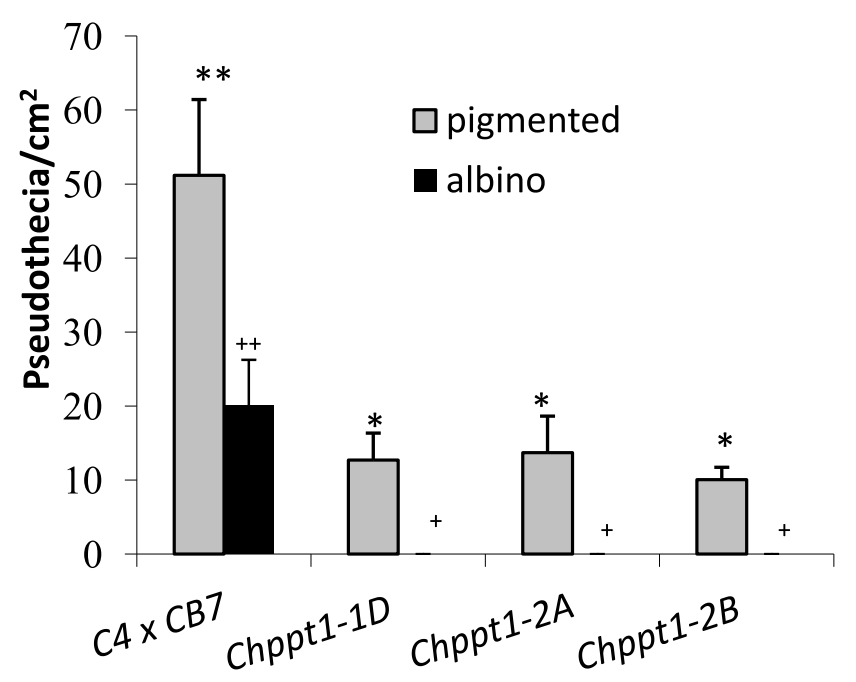

Strains

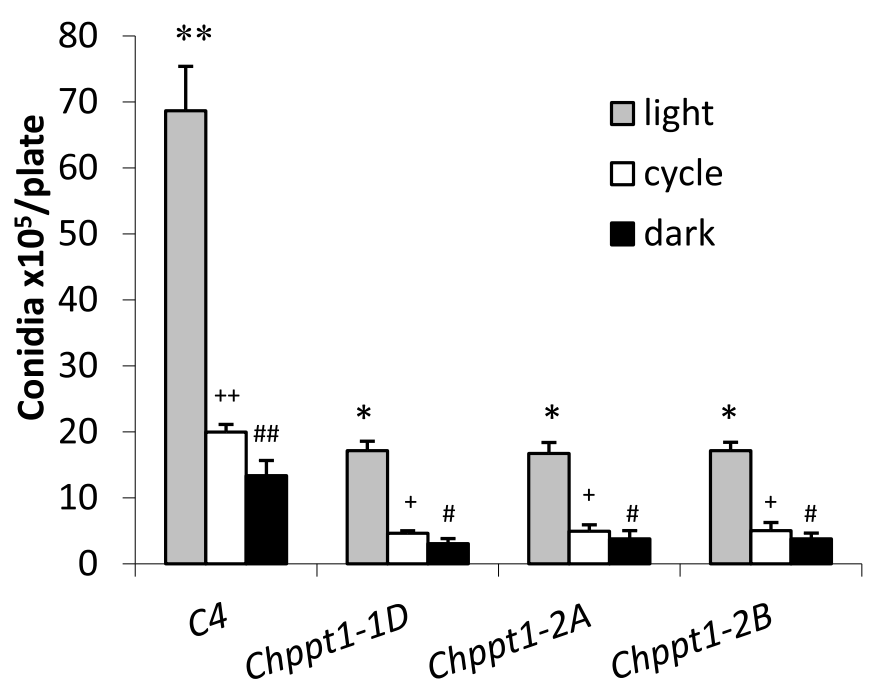

Strains

Fig. 8. Cochliobolus heterostrophus ppt1 mutants are female-sterile and are reduced in production of asexual spores. A, Chppt1 mutants are female-sterile. Top left, a control cross between wild-type (WT) strain C4 (MAT1-2, pigmented and the strain in which ppt1 mutants were made) and WT strain CB7 (MAT1-1, albino). The cross produced both pigmented and albino (arrow) pseudothecia, indicating the strains are female-fertile and hermaphroditic. Top right and bottom, all crosses between ppt1 mutants (albino) and WT C5 (pigmented) produced only pigmented pseudothecia, indicating the mutants are female-sterile and can only act as males; they are not hermaphroditic. B, The Chppt1 mutant crosses to pigmented WT strain C5 produced significantly fewer pseudothecia than WT crosses. No albino pseudothecia formed in mutant crosses. Error bars are standard deviation. Different symbols indicate significant differences at $P<$ 0.05 in $t$ test analysis in which each strain of each color was compared with WT strain C4. C, Asexual sporulation of Chppt1mutants during vegetative growth on complete medium with $1 \%$ xylose plates was significantly less than that of WT strain C4 under all light conditions but follows the same general pattern in that more are produced in the light. Error bars are standard deviation. Different symbols indicate significant differences at $P<0.05$ in $t$ test analysis in which each strain of each color was compared with WT strain C4. 
sizes (Fig. 2D). In this case, for C. miyabeanus, we have single nps6 mutants (Oide et al. 2006) but no double-mutant data, thus the metabolites absent and responsible for reduction of virulence are unknown but, as for $C$. heterostrophus, likely involve both types of siderophore. Note that in the current experiment, we used mycelial fragments prepared as described below for inoculation, because ppt 1 mutants produce no or very few spores. Elsewhere, we have shown that inoculation with $C$. heterostrophus (Horwitz et al. 1999) and C. miyabeanus (De Bruyne et al. in press) mycelial fragments produces lesions comparable to those resulting from spores.

In fungi, Ppt1 also activates $\alpha$-aminoadipate reductase, an NRPS responsible for lysine biosynthesis. We have demonstrated that we can effectively add supplemental lysine to restore WT growth in vitro (Fig. 1B) and that we can augment lesion formation in planta (Fig. 2B). Thus, reduced virulence of the ppt 1 mutants is not attributable to lack of lysine and is likely attributable to absence of one or more secondary metabolites that impact pathogenic development, including those that manage reactive oxygen species (such as siderophores). Furthermore, although ppt 1 mutants of the hemibiotrophs Colletotrichum graminicola and Magnaporthe oryzae are blocked in disease progression because they are unable to form WT appressoria due to lack of melanin (Horbach et al. 2009; Nosanchuk and Casadevall 2003), C. heterostrophus albino mutants are fully able to form appressoria and to cause disease; thus, melanin is not required for virulence in this case (Eliahu et al. 2007).

We note that Ppt1 plays a role in production of conidia, which are the infective propagules of $C$. heterostrophus, $C$. victoriae, and $C$. miyabeanus. This finding is in agreement with previous work on Aspergillus nidulans (Márquez-Fernández et al. 2007), C. sativus (Leng and Zhong 2012), Trichoderma virens (Velázquez-Robledo et al. 2011), and Colletotrichum graminicola (Horbach et al. 2009). C. sativus pptl mutants, for example, produced only one-quarter as many conidia as were produced by WT. For $C$. heterostrophus, reduction in conidium production should not be a factor contributing to reduced virulence in our plant assay, however, as equal numbers of WT and mutant conidia were used for inoculation and conidium germination rate is not affected (not shown). For C. miyabeanus mutants, we used mycelium fragments as inoculum, as noted above.

Regarding our second goal, our results indicate that Ppt1 is required for production of the HST T-toxin by C. heterostrophus race $\mathrm{T}$, since the corresponding ppt 1 mutants were unable to produce the toxin (Fig. 3), which requires the enzymatic activity of two PKS (Baker et al. 2006; Inderbitzin et al. 2010). Although this is expected to be the case, based on other work that shows that Ppt 1 is needed for activation of all PKS and NRPS (Márquez-Fernández et al. 2007), this is the first formal proof.

For $C$. victoriae pptl mutants, we predict that victorin biosynthesis requires an NRPS or NRPS:PKS hybrid synthetase (Condon et al. 2013), based on structure of victorin (a cyclic pentapeptide) and the mechanism of biosynthesis of other known secondary metabolites, including HST. Thus, our expectation was that a ppt1 mutant should not make victorin. To test this, we used a crude but diagnostic leaf bioassay in which we compared phenotypes of WT and mutant strains on susceptible (carrying the dominant $V b$ gene) and resistant ( $v b v b$ genotype) oats. Susceptible leaves assayed in filtrate from WT strains producing victorin were wilted and shriveled, while resistant leaves remained erect and green. Filtrates of two independent ppt 1 mutants were tested and, in both, susceptible and resistant leaves remained erect and green. We conclude that victorin production by ppt 1 mutants is absent or greatly reduced and that a PKS, NRPS, or hybrid enzyme is, as predicted, involved in victorin production.
Finally, our data also indicate that loss of PPT1 can lead to overproduction of secondary metabolites, such as terpenes, that are not made via PKS or NRPS pathways. We found that production of the sesterterpenoid non-HST ophiobolin A was increased 10.6 times in C. miyabeanus pptl mutants compared with WT. We are aware of only one other report of this phenomenon in fungi. Deletion of PPT1 in Fusarium fujikuroi results in a strain that shows enhancement in terpene-derived metabolites such as gibberellic acid and volatile substances such as $\alpha$-acorenol (Wiemann et al. 2012). These findings and ours point to possible strategies for changing production ratios of individual secondary metabolites.

The aerial mycelial surface of Chppt1 and Cmppt1 mutant colonies are hydrophilic, in contrast to WT colony surfaces, which are hydrophobic. This phenotype is also present for mutants lacking the $C$. heterostrophus NRPS Nps4, which biosynthesizes a yet to be determined metabolite (Turgeon et al. 2008). It is not associated with melanin production (colony surfaces of mutants deleted for $P K S 18$ [responsible for melanin production] do not become hydrophilic) or with hydrophobins (nps 4 mutants are WT for hydrophobin genes [unpublished]).

\section{MATERIALS AND METHODS}

\section{Fungal strains and culturing conditions.}

All $C$. heterostrophus mutants were constructed in the WT inbred lab strain C4 (American Type Culture Collection [ATCC] 48331, MAT1-2). C. miyabeanus mutants were derived from the WT field strain WK1C (ATCC 56640, MAT1-2), and C. victoriae mutants were derived from the WT field strain FI3 (Condon et al. 2013). Three independent $C$. heterostrophus ppt1 mutants (Chppt1-1D, Chppt1-2A, and Chppt1-2B), three C. miyabeanus mutants (Cmppt1-1, Cmppt1-4, and Cmppt1-8), and four C. victoriae mutants (Cvppt1-2, Cvppt1-3, Cvppt1-4, and Cvppt1-7) were used in this study (Table 1). The Chnps $2 n p s 6$ strain 1495-T1-1, which lacks genes encoding the NRPS responsible for intra- and extracellular siderophore production, was included for comparisons of virulence (Condon et al. 2014a; Oide et al. 2007; Zhang et al. 2013). C. heterostrophus and C. miyabeanus strains were grown on CMX (Tzeng 1990) under a 16-h fluorescent light and 8-h dark cycle at $23 \pm 1^{\circ} \mathrm{C}$, while C. victoriae strains were grown on CMX or oatmeal agar.

\section{Identification of $C$. heterostrophus and C. miyabeanus PPT1 genes.}

The Aspergillus nidulans (Emericella nidulans) NpgA protein sequence (GenBank accession number AF198117) was used as a BLAST query against the C. heterostrophus C5 database (JGI portal) for initial identification of the ortholog in C. heterostrophus. The C5 protein was used to query the C. heterostrophus strain C4 (JGI portal), C. miyabeanus WK1C and $C$. victoriae FI3 (JGI MycoCosm databases) genome sequences (Grigoriev et al. 2014), and a single ortholog was identified in each genome $(C$. heterostrophus $\mathrm{C} 4$ protein ID 23829, C. miyabeanus protein ID 88023, C. victoriae protein ID 110360).

\section{Phylogenetic analyses.}

The $C$. heterostrophus Ppt1 amino acid sequence was used as a tBLASTx query against the Dothideomycete genome protein sequences (JGI MycoCosm homepage) from the species indicated. Ppt1 protein sequences of Eurotiomycetes fungi, Penicillium chrysogenum and three Aspergillus species were also used. Ppt1 proteins were aligned with ClustalW (Larkin et al. 2007). A phylogenetic tree was constructed using MEGA 
version 6 (Tamura et al. 2013) and bootstrap analysis with 1,000 replicates was carried out. The best protein evolutionary model was decided using the ProtTest web server (Abascal et al. 2005).

\section{PPT1 gene deletions and confirmation of gene deletion.}

The PPT1 genes were deleted, using the split-marker method (Catlett et al. 2003). The 5' and $3^{\prime}$ flanking sequences of the predicted open reading frame (ORF) of each target gene were amplified from WT strains $\mathrm{C} 4$, WK1C, and FI3, using two specific primer sets for each gene that matched upstream and downstream PPT1 gene flanking sequences (Supplementary Table S1). All primers were designed using Gene Runner 3.05 and 4.0.9.3 Beta software and Primer3 plus software. PCR amplification of transformation constructs was carried out with iProof high-fidelity DNA polymerase (Bio-Rad, Hercules, CA, U.S.A), following the manufacturer's instructions. The predicted $P P T 1$ ORF of the PPT1 genes were completely deleted and were replaced with the $h y g B$ cassette from pUCATPH (Lu et al. 1994), which confers resistance to hygromycin B (Wu et al. 2012).

All PCR amplifications for confirmation of gene deletion were conducted with GoTaq polymerase (Promega Corp., Madison, WI, U.S.A.). Deletion of the PPT1 in candidate strains was verified by PCR amplification, using three diagnostic primer sets as described by Inderbitzin et al. (2010). For all three fungi, one set of primers amplified an internal region of the target gene; a PCR product is expected from WT and ectopic transformants but should be missing from ppt1 mutants. The two additional primer sets confirm correct insertions into the $5^{\prime}$ and $3^{\prime}$ regions flanking the target gene. For these, a specific primer matching sequence outside the $5^{\prime}$ or $3^{\prime}$ flanking sequences used for deletion and a primer in the $h y g B$ gene (NLC37 or NLC38) were used. Only ppt 1 deletion strains yield a PCR product; these bands will not be present in WT and ectopic strains (Inderbitzin et al. 2010).

DNA isolation and transformation.

Genomic DNA of all strains was isolated, using the Ultra Clean microbial DNA isolation kit (Mo-Bio, Carlsbad, CA, U.S.A.),

Table 1. Cochliobolus species and strains used in this study

\begin{tabular}{|c|c|c|}
\hline Species/strain & Genotypes & $\begin{array}{l}\text { Genetic background/ } \\
\text { reference }\end{array}$ \\
\hline \multicolumn{3}{|c|}{ C. heterostrophus } \\
\hline $\mathrm{C} 4$ & MAT1-2, Tox $1^{+}$ & $\begin{array}{l}\text { ATCC } 48331 \text { (Leach and } \\
\text { Yoder 1982) }\end{array}$ \\
\hline $\mathrm{C} 5$ & MAT1-1, Tox1- & $\begin{array}{l}\text { ATCC } 48332 \text { (Leach and } \\
\text { Yoder 1982) }\end{array}$ \\
\hline CB7 & MAT1-1, alb1, Tox $1^{+}$ & $\begin{array}{l}\text { B30-A3-R-20 (Oide et al. } \\
\text { 2007) }\end{array}$ \\
\hline 1495-T1-1 & $\begin{array}{l}\text { nps } 2 \text { nps6, MAT1-1, Tox } 1^{+} \\
\quad \text { hygB }\end{array}$ & C4 (Oide et al. 2007) \\
\hline Chppt1-1D & ppt1, MAT1-1, hyg $B^{R}$ & $\mathrm{C} 4$; this study \\
\hline Chppt1-2A & ppt1, MAT1-1, hygB $B^{R}$ & $\mathrm{C} 4$, this study \\
\hline Chppt1-2B & ppt1, MAT1-1, hygB $B^{R}$ & $\mathrm{C} 4$; this study \\
\hline \multicolumn{3}{|l|}{ C. miyabeanus } \\
\hline WK1C & MAT1-2 & Chang 1980 \\
\hline Cmppt1-1 & ppt1, MAT1-2, hygB $B^{R}$ & WK1C, this study \\
\hline Cmppt1-4 & ppt1, MAT1-2, hygB $B^{R}$ & WK1C; this study \\
\hline Cmppt1-8 & ppt1, MAT1-2, hyg $B^{R}$ & WK1C, this study \\
\hline \multicolumn{3}{|l|}{ C. victoriae } \\
\hline FI3 & $M A T 1-2$ & Arie et al. 1997 \\
\hline Cvppt1-2 & ppt1, MAT1-2, hygB $B^{R}$ & FI3, this study \\
\hline Cvppt1-3 & ppt1, MAT1-2, hygB $B^{R}$ & FI3, this study \\
\hline Cvppt1-4 & ppt1, MAT1-2, hygB ${ }^{R}$ & FI3, this study \\
\hline Cvppt1-7 & ppt1, MAT1-2, hyg $B^{R}$ & FI3, this study \\
\hline
\end{tabular}

according to the manufacturer's instructions. Unless otherwise mentioned, all PCR analyses were performed using PCR master mix (Promega Corp.) following the manufacturer's recommendations.

Transformation of $C$. heterostrophus, C. victoriae, and C. miyabeanus was carried out as previously described (Inderbitzin et al. 2010; Oide et al. 2006), with a slight modification for C. miyabeanus. C. miyabeanus was cultured on CMX for 14 days under constant light. $C$. victoriae was cultured on oatmeal agar. For protoplasting, conidia were transferred to $300 \mathrm{ml}$ of complete medium $(\mathrm{CM})$ in a 1-liter flask and were shaken at $100 \mathrm{rpm}$ for 20 to $24 \mathrm{~h}$ in the dark at $24^{\circ} \mathrm{C}$. Protoplasts were harvested and transformed as described previously (Wu et al. 2012). Candidate transformants were single-conidiated and were transferred to CMX without salts containing hygromycin B $(100 \mu \mathrm{g} / \mathrm{ml})$ in the case of $C$. heterostrophus and $C$. miyabeanus or to lactose casein agar (Xue et al. 2013) containing hygromycin B $(50 \mu \mathrm{g} / \mathrm{ml})$ in the case of $C$. victoriae, to confirm sensitivity to the drug, as described previously (Oide et al. 2006). All strains were stored in $25 \% \mathrm{CM}$ glycerol at $-80^{\circ} \mathrm{C}$.

\section{Growth.}

For comparison of ppt1 mutant growth to WT, a 6-mm diameter plug from the edge of 7-day-old colonies was placed on $\mathrm{CMX}$ and the plate was incubated at $23^{\circ} \mathrm{C}$ under a 12-h-light and 12-h-dark cycle. Cultures plates were incubated for 1 and 2 weeks, respectively, for $C$. heterostrophus and $C$. miyabeanus.

Strains deleted for $P P T 1$ are expected to require supplemental lysine for growth (Keszenman-Pereyra et al. 2003; Leng and Zhong 2012; Wiemann et al. 2012). To confirm lysine deficiency, all strains were plated as above on CMX, minimal medium (MM), and MM supplemented with $50 \mu \mathrm{g}$ of lysine per milliliter. Cultures were grown as described above.

\section{Virulence assay.}

To examine the virulence phenotype of Chpptl mutants and WT, 21-day-old maize seedlings (variety W64A-N) were inoculated (Oide et al. 2006) with $2 \mathrm{ml}$ per plant of a conidial suspension $\left(2 \times 10^{4} / \mathrm{ml}\right)$ containing $0.02 \%$ Tween 20 plus or minus lysine $(50 \mu \mathrm{g} / \mathrm{ml})$. Conidia were taken from 7-day-old cultures grown on CMX. For Cmppt 1 mutants and WT, plant inoculation followed that described by Park et al. (2008), with slight modification for rice and C. miyabeanus. Cmppt1 mutants produce few to no conidia, thus 5-week-old rice seedling leaves (variety Nipponbare) were inoculated with $20 \mu \mathrm{l}$ of mycelial suspension, at a concentration of approximately $2 \times 10^{5}$ mycelial fragments per milliliter of 5-day-old cultures of WT and ppt1 mutants grown on CMX, containing $0.02 \%$ Tween 20 supplemented with $50 \mu \mathrm{g}$ of lysine per milliliter. A syringe needle was used to make a wound on leaves prior to inoculation.

After inoculation, plants were incubated in a mist chamber at $25^{\circ} \mathrm{C}$ with $72 \%$ relative humidity overnight and, then, were transferred to a growth chamber for 4 (C. heterostrophus) or 9 (C. miyabeanus) days, at $25^{\circ} \mathrm{C}$ under a 16-h-light and 8-h-dark cycle. Symptoms were monitored and photographed at 5 and 10 dpi for corn and rice, respectively. Lesion sizes were measured and data was analyzed using a one-way analysis of variance module of SPSS 17.00 (SPSS Inc., Chicago). On corn, the length of necrotic symptoms associated with individual lesions was measured for 50 lesions; for rice, 10 lesions were measured. All treatments and control were repeated three times and five plants were used for each fungal strain.

\section{T-toxin assay.}

The microbial assay was used to investigate the role of Ppt1 in T-toxin biosynthesis by $C$. heterostrophus race $\mathrm{T}$ strain $\mathrm{C} 4$ (Ciuffetti et al 1992). Escherichia coli DH5 $\alpha$ cells carrying the 
Turf13 plasmid pATH13-T were uniformly spread on Luria broth + ampicillin plates, and plates were inoculated with 4-mm mycelial plugs of Chppt1 mutants, along with WT C4 as the race $\mathrm{T}$ positive control and $\mathrm{WT} \mathrm{C} 5$ as the race $\mathrm{O}$ negative control for T-toxin. The plates were incubated overnight at $30^{\circ} \mathrm{C}$. Clear zones in the bacterial lawn surrounding mycelial plugs indicate a positive toxin reaction.

\section{Victorin assay.}

Cultures of WT and two ppt1 mutants (strains Cvppt1-2, Cvppt 1-3) were started from glycerol stocks at $-80^{\circ} \mathrm{C}$ on $\mathrm{CMX}$ or oatmeal agar plates and were grown for 1 week as described above. Ten small plugs from each plate were transferred to $20 \mathrm{ml}$ of Fries liquid medium (Pringle and Braun 1957) containing $50 \mu \mathrm{g}$ of lysine per milliliter supplement and were grown for 12 days in the dark with very gentle shaking. Filtrates were harvested by filtering out mycelium. For victorin assays, 1-ml aliquots of undiluted, 1:10, and 1:100 dilutions of culture filtrate were placed in glass tubes, and cut leaves of susceptible (Fulgrain) and resistant (Red Rustproof) oats were placed in the filtrates. Leaves were observed daily for 3 days.

\section{Quantification of ophiobolin A using LC-MS/MS.}

Three mycelium plugs per strain of Cmppt1-1 and WT strain WK1C were grown in 100-ml Erlenmeyer flasks containing $30 \mathrm{ml}$ of Fries medium (Pringle and Braun 1957) supplemented with $0.1 \%$ yeast extract and $1 \mathrm{ml}$ of plant extract, at $28^{\circ} \mathrm{C}$ in the dark on a rotary shaker $(150 \mathrm{rpm})$. The plant extract was prepared by extracting $4 \mathrm{~g}$ of ground fresh rice leaves with $50 \mathrm{ml}$ of doubledistilled water and was filter-sterilized, using a syringe-driven 0.22- $\mu \mathrm{m}$ Millex-HV filter unit (Merck Millipore, Cork, Ireland) before use. After 3 days, the culture was blended and $1 \mathrm{ml}$ was transferred to fresh medium and was incubated for another 7 days under the same circumstances. The supernatant was filtered through two layers of cheesecloth and one layer of filter paper (grade 3 hw; Sartorius Stedim Biotech S.A., Goettingen, Germany) and was sterilized, using a syringe-driven $0.45-\mu \mathrm{m}$ Millex-HV filter unit (Merck Millipore). The mycelium was collected from the filter and was dried at $80^{\circ} \mathrm{C}$ for $24 \mathrm{~h}$ before weighing. The total volume of the crude culture filtrate was measured and a 4-ml aliquot extracted with $10 \mathrm{ml}$ of ethyl acetate/acetonitril ( $1: 1 \mathrm{vol} / \mathrm{vol})$ after the addition of $1.8 \mathrm{~g}$ of $\mathrm{MgSO}_{4}$. The sample was vigorously shaken on an end-over-end shaker (Agitelec, J. Toulemonde \& Cie, Paris) for $30 \mathrm{~min}$ and was then centrifuged at $4,000 \times g$ for $15 \mathrm{~min}$. The organic upper phase was evaporated to dryness under an $\mathrm{N}_{2}$ flow at $40^{\circ} \mathrm{C}$. The dry residue was redissolved in $100 \mu \mathrm{l}$ of mobile phase A/B (60:40 $\mathrm{vol} / \mathrm{vol}$ ) and was filter-centrifuged in an Ultrafree-MC centrifugal filter unit (Merck Millipore, Bedford, MA, U.S.A.) for 5 mins at $14,000 \times g$.

A Waters Acquity ultra-performance liquid chromatographic system coupled to a Waters Quattro Premier XE tandemquadrupole mass spectrometer (Waters, Milford, MA, U.S.A.) was used to analyze the samples. The column used was a Zorbax Eclipse C18 column $(100 \times 2.1 \mathrm{~mm}$, i.d. $1.8 \mu \mathrm{m})$ (Agilent, Santa Clara, CA, U.S.A.). Data processing was done with Masslynx software v4.1 (Waters).

The LC-MS/MS method used was as follows. The column used was kept at $30^{\circ} \mathrm{C}$ and the injection volume was $10 \mu \mathrm{l}$. Mobile phase A consisted of $\mathrm{H}_{2} \mathrm{O} /$ methanol 95:5 (vol/vol) and mobile phase $\mathrm{B}$ of methanol/ $\mathrm{H}_{2} \mathrm{O} 95: 5$ ( $\mathrm{vol} / \mathrm{vol}$ ). To both mobile phases, $0.1 \%$ formic acid and $1 \mathrm{mM}$ ammonium formate was added to facilitate ionization. A gradient program was used at a flow rate of $0.4 \mathrm{ml} / \mathrm{min}$. The gradient started at $99.1 \%$ mobile phase $\mathrm{A}$, which was held for $0.5 \mathrm{~min}$ and, next, was linearly decreased to $0.9 \%$ in 19.5 mins. An isocratic period of
$100 \%$ mobile phase B started was held for 1 min. Initial column conditions were reached at $24 \mathrm{~min}$, using a linear decrease of mobile phase $\mathrm{B}$, and the column was reconditioned for $4 \mathrm{~min}$ prior to the following injection. The mass spectrometer was operated in the positive electrospray ionization mode. The capillary voltage was $3.5 \mathrm{kV}$, and nitrogen was used as the desolvation gas. Source and desolvation temperatures were set at 120 and $300^{\circ} \mathrm{C}$, respectively. Ophiobolin A was analyzed using selected reaction monitoring mode, with the following ion transitions: 401 to 109 (cone $40 \mathrm{~V}$, collision energy $20 \mathrm{eV}$ ), 401 to 365.2 (cone $40 \mathrm{~V}$, collision energy $10 \mathrm{eV}$ ). Ion transition 401 to 365.2 was used for quantification; ion transition 401.0 to 109.0 was used as qualifier.

Quanlynx (Waters) was used for quantification of ophiobolin $\mathrm{A}$ in the samples by generating a calibration curve, using different concentrations of an ophiobolin A standard (Tebu Bio, Boechout, Belgium). Ophioblin A production per gram of mycelium dry weight was calculated. Statistical analysis of three biological replicates was performed using a two-sided student $t$ test $(P=0.05)$ (TIBCO Spotfire $S+8.2$ for Windows).

\section{Oxidative stress and sensitivity to iron depletion.}

To evaluate sensitivity of ppt 1 mutants to oxidative stress, 4-mm mycelial plugs of strains were grown on MM supplemented with lysine $(50 \mu \mathrm{g} / \mathrm{ml})$ amended with $\mathrm{H}_{2} \mathrm{O}_{2}$ at concentrations of $0,0.5,1.0,2.0,4.0$, and $8.0 \mathrm{mM}$ (or $0,2.0,4.0$ in the case of C. victoriae) (Oide et al. 2006). Sensitivity to iron depletion was examined by growing mycelial plugs of Chppt1, Cmppt1, and WT strains on MM supplemented lysine $(50 \mu \mathrm{g} / \mathrm{ml})$ amended with the iron chelator 2, 2'-dipyridyl (2-DP) at 0,25 , $50,100,200$, and $400 \mu \mathrm{M}$ concentrations. The minimal inhibition concentrations for each strain were determined by measuring the radius of the colony on MM with various concentrations of each stressor and comparison with growth of WT under the same condition.

For both stressor tests, plates were incubated for 7 days at $23^{\circ} \mathrm{C}$ in complete dark and three replicates were prepared for each strain. All experiments were repeated four times.

\section{Hydrophobicity test.}

Surface hydrophobicity of $C$. heterostrophus and C. miyabeanus WT and mutants was examined by applying a $10-\mu \mathrm{l}$ water droplet onto the surface of 8-day-old colonies as described (Sevim et al. 2012). Each strain was photographed at the time of application of the water droplet and after the droplet was gone.

\section{Sexual and asexual development.}

For sexual development, crosses were done for $C$. heterostrophus only. Crosses were set up as previously described (Leach and Yoder 1982). Strains were plated on Sach's medium and were incubated for 3 weeks at $23^{\circ} \mathrm{C}$ in the dark. Control crosses included pigmented WT C4 $(M A T 1-2 ; A L B 1) \times$ albino CB7 (MAT1-1, alb1). Each Chppt1 (MAT1-2; ALB1) mutant strain (functionally albino) was crossed to the WT pigmented strain $\mathrm{C5}$ (MAT1-1;ALB1). The ability of each strain to act as female was assessed by monitoring for the presence or absence of albino pseudothecia. The number of pigmented and albino pseudothecia per square centimeter of corn leaf was calculated and recorded for each cross plate.

To examine fertility of crosses, 25 pseudothecia from each cross plate were squeezed open individually. The number of asci in each pseudothecium and the number of mature ascospores in each ascus were recorded.

Since the $C$. victoriae and $C$. miyabeanus ppt 1 mutants do not produce conidia on CMX, asexual development during vegetative growth was examined for $C$. heterostrophus only. Conidia from fully grown cultures on 100 - by $15-\mathrm{mm}$ CMX plates were 
collected at 7 days. Plates were completely scraped with a $0.02 \%$ Tween 20 solution, scrapings were filtered through cheesecloth, and dilution series of the conidial suspensions were counted, using a hemocytometer, and were recorded.

\section{ACKNOWLEDGMENTS}

The authors thank K. Loeffler, Section of Plant Pathology and PlantMicrobe Biology photo lab, for outstanding photographic assistance. N. A I. Mohd Zainudin was supported by the Universiti Putra Malaysia (UPM) and the Ministry of Higher Education (MOHE). L. De Bruyne was supported by a Ph.D. Grant for Strategic Basic Research provided by the agency for Innovation by Science and Technology (IWT), Belgium. Q. B was supported by Nankai University and the China Scholarship Council W. Li was supported by a Jiangsu Academy of Agricultural Sciences (JAAS) Overseas Studies Scholarship.

\section{LITERATURE CITED}

Abascal, F., Zardoya, R., and Posada, D. 2005. ProtTest: Selection of bestfit models of protein evolution. Bioinformatics 21:2104-2105.

Ahn, I. P., Kim, S., Kang, S., Suh, S. C., and Lee, Y. H. 2005. Rice defense mechanisms against Cochliobolus miyabeanus and Magnaporthe grisea are distinct. Phytopathology 95:1248-1255.

Allen, G., Bromley, M., Kaye, S. J., Keszenman-Pereyra, D., Zucchi, T. D., Price, J., Birch, M., Oliver, J. D., and Turner, G. 2011. Functional analysis of a mitochondrial phosphopantetheinyl transferase (PPTase) gene pptB in Aspergillus fumigatus. Fungal Genet. Biol. 48:456-464.

Arie, T., Christiansen, S. K., Yoder, O. C., and Turgeon, B. G. 1997. Efficient cloning of ascomycete mating type genes by PCR amplification of the conserved MAT HMG Box. Fungal Genet. Biol. 21:118-130.

Baker, S. E., Kroken, S., Inderbitzin, P., Asvarak, T., Li, B. Y., Shi, L., Yoder, O. C., and Turgeon, B. G. 2006. Two polyketide synthaseencoding genes are required for biosynthesis of the polyketide virulence factor, T-toxin, by Cochliobolus heterostrophus. Mol. Plant-Microbe Interact. 19:139-149.

Catlett, N. L., Lee, B.-N., Yoder, O. C., and Turgeon, B. G. 2003. Splitmarker recombination for efficient trageted deletion of fungal genes. Fungal Genet. Newsl. 50:9-11.

Chang, H. S. 1980. Inheritance of light dependence for sporulation in Cochliobolus miyabeanus. T. Brit. Mycol. Soc. 74:642-643.

Christiansen, S. K., Wirsel, S., Yoder, O. C., and Turgeon, B. G. 1998. The two Cochliobolus mating type genes are conserved among species but one of them is missing in C. victoriae. Mycol. Res. 102:919-929.

Ciuffetti, L., Yoder, O., and Turgeon, B. G. 1992. A microbiological assay for host-specific fungal polyketide toxins. Fungal Genet. Newsl. 39:18-19.

Condon, B. J., Leng, Y., Wu, D., Bushley, K. E., Ohm, R. A., Otillar, R., Martin, J., Schackwitz, W., Grimwood, J., MohdZainudin, N. A. I., Xue, C., Wang, R., Manning, V. A., Dhillon, B., Tu, Z. J., Steffenson, B. J., Salamov, A., Sun, H., Lowry, S., LaButti, K., Han, J., Copeland, A., Lindquist, E., Barry, K., Schmutz, J., Baker, S. E., Ciuffetti, L. M., Grigoriev, I. V., Zhong, S. and Turgeon, B. G. 2013. Comparative genome structure, secondary metabolite and effector coding capacity across Cochliobolus pathogens. PLOS Genet. 9:e1003233.

Condon, B. J., Oide, S., Gibson, D. M., Krasnoff, S. B., and Turgeon, B. G 2014a. Reductive iron assimilation and intracellular siderophores assist extracellular siderophore-driven iron homeostasis and virulence. Mol. Plant-Microbe Interact. 27:793-808.

Condon, B. J., Wu, D., Kraševec, N., Horwitz, B. A., and Turgeon, B. G 2014b. Comparative genomics of Cochliobolus phytopathogens. Pages 41-67 in: Genomics of Plant-Associated Fungi: Monocot Pathogens. R. A. Dean, A. Lichens-Park, and C. Kole, eds. Springer, Berlin.

Copp, J. N., and Neilan, B. A. 2006. The phosphopantetheinyl transferase superfamily: Phylogenetic analysis and functional implications in cyanobacteria. Appl. Environ. Microbiol. 72:2298-2305.

Crawford, J. M., Vagstad, A. L., Ehrlich, K. C., Udwary, D. W., and Townsend, C. A. 2008. Acyl-carrier protein-phosphopantetheinyltransferase partnerships in fungal fatty acid synthases. ChemBioChem 9:1559-1563.

De Bruyne, L., Van Poucke, C., Diana Di Mavungu, J., and Mohd Zainudin, N. A. I. Vanhaecke, L., De Vleesschauwer, D., Turgeon, G. De Saeger, S. and Hofte, M. Comparative chemical screening and genetic analysis reveal tentoxin as a new virulence factor in Cochliobolus miyabeanus, the causal agent of brown spot disease on rice. Mol. Plant Pathol. In press.

Eliahu, N., Igbaria, A., Rose, M. S., Horwitz, B. A., and Lev, S. 2007. Melanin biosynthesis in the maize pathogen Cochliobolus heterostrophus depends on two mitogen-activated protein kinases, Chk1 and Mps1, and the transcription factor Cmr1. Eukaryot. Cell 6:421-429.

Grigoriev, I. V., Nikitin, R., Haridas, S., Kuo, A., Ohm, R., Otillar, R., Riley, R., Salamov, A., Zhao, X., Korzeniewski, F., Smirnova, T., Nordberg, H., Dubchak, I., and Shabalov, I. 2014. MycoCosm portal: Gearing up for 1000 fungal genomes. Nucleic Acids Res. 42:D699-D704.

Horbach, R., Graf, A., Weihmann, F., Antelo, L., Mathea, S., Liermann, J. C., Opatz, T., Thines, E., Aguirre, J., and Deising, H. B. 2009. Sfp-type $4^{\prime}$-phosphopantetheinyl transferase is indispensable for fungal pathogenicity. Plant Cell 21:3379-3396.

Horwitz, B. A., Sharon, A., Lu, S. W., Ritter, V., Sandrock, T. M., Yoder, O. C., and Turgeon, B. G. 1999. A G protein alpha subunit from Cochliobolus heterostrophus involved in mating and appressorium formation. Fungal Genet. Biol. 26:19-32.

Huang, Y., Wendt-Pienkowski, E., and Shen, B. 2006. A dedicated phosphopantetheinyl transferase for the fredericamycin polyketide synthase from Streptomyces griseus. J. Biol. Chem. 281:29660-29668.

Inderbitzin, P., Asvarak, T., and Turgeon, B. G. 2010. Six new genes required for production of T-toxin, a polyketide determinant of high virulence of Cochliobolus heterostrophus to maize. Mol. Plant-Microbe Interact. 23:458-472

Keszenman-Pereyra, D., Lawrence, S., Twfieg, M. E., Price, J., and Turner, G. 2003. The npgA/ cfwA gene encodes a putative $4^{\prime}$-phosphopantetheinyl transferase which is essential for penicillin biosynthesis in Aspergillus nidulans. Curr. Genet. 43:186-190.

Lambalot, R. H., Gehring, A. M., Flugel, R. S., Zuber, P., LaCelle, M., Marahiel, M. A., Reid, R., Khosla, C., and Walsh, C. T. 1996. A new enzyme superfamily-The phosphopantetheinyl transferases. Chem. Biol. 3:923-936

Larkin, M. A., Blackshields, G., Brown, N. P., Chenna, R., McGettigan, P. A., McWilliam, H., Valentin, F., Wallace, I. M., Wilm, A., Lopez, R. Thompson, J. D., Gibson, T. J., and Higgins, D. G. 2007. Clustal W and Clustal X version 2.0. Bioinformatics 23:2947-2948.

Leach, J., and Yoder, O. C. 1982. Heterokaryosis in Cochliobolus heterostrophus. Exp. Mycol. 6:364-374.

Lee, B. N., Kroken, S., Chou, D. Y., Robbertse, B., Yoder, O. C., and Turgeon, B. G. 2005. Functional analysis of all nonribosomal peptide synthetases in Cochliobolus heterostrophus reveals a factor, NPS6, involved in virulence and resistance to oxidative stress. Eukaryot. Cell 4:545-555.

Leng, Y., and Zhong, S. 2012. Sfp-type 4'-phosphopantetheinyl transferase is required for lysine synthesis, tolerance to oxidative stress and virulence in the plant pathogenic fungus Cochliobolus sativus. Mol. Plant Pathol. 13. 375-387.

Lu, S. W., L. Lyngholm, G. Yang, C. R. Bronson, O. C. Yoder, and B. G. Turgeon. 1994. Tagged mutations at the Tox1 locus of Cochliobolus heterostrophus using restriction enzyme mediated integration. Proc. Natl. Acad. Sci. 91:12649-12653.

Macko, V., Wolpert, T. J., Acklin, W., Jaun, B., Seibl, J., Meili, J., and Arigoni, D. 1985. Characterization of victorin C, The major hostselective toxin from Cochliobolus victoriae: Structure of degradation products. Experientia 41:1366-1370.

Márquez-Fernández, O., Trigos, A., Ramos-Balderas, J. L., ViniegraGonzález, G., Deising, H. B., and Aguirre, J. 2007. Phosphopantetheinyl transferase CfwA/NpgA is required for Aspergillus nidulans secondary metabolism and asexual development. Eukaryot. Cell 6:710-720.

Nosanchuk, J. D., and Casadevall, A. 2003. The contribution of melanin to microbial pathogenesis. Cell. Microbiol. 5:203-223.

Oberegger, H., Eisendle, M., Schrettl, M., Graessle, S., and Haas, H. 2003 $4^{\prime}$-phosphopantetheinyl transferase-encoding npgA is essential for siderophore biosynthesis in Aspergillus nidulans. Curr. Genet. 44:211-215.

Oide, S., Krasnoff, S. B., Gibson, D. M., and Turgeon, B. G. 2007. Intracellular siderophores are essential for ascomycete sexual development in heterothallic Cochliobolus heterostrophus and homothallic Gibberella zeae. Eukaryot. Cell 6:1339-1353.

Oide, S., Moeder, W., Krasnoff, S., Gibson, D., Haas, H., Yoshioka, K., and Turgeon, B. G. 2006. NPS6, encoding a nonribosomal peptide synthetase involved in siderophore-mediated iron metabolism, is a conserved virulence determinant of plant pathogenic ascomycetes. Plant Cell 18:2836-2853

Park, D.-S., Sayler, R. J., Hong, Y.-G., Nam, M.-H., and Yang, Y. 2008. A method for inoculation and evaluation of rice sheath blight disease. Plant Dis. 92:25-29.

Pringle, R. B., and Braun, A. C. 1957. The isolation of the toxin of Helminthosporium victoriae. Phytopathology 47:369-71.

Quadri, L. E., Weinreb, P. H., Lei, M., Nakano, M. M., Zuber, P., and Walsh, C. T. 1998. Characterization of Sfp, a Bacillus subtilis phosphopantetheinyl transferase for peptidyl carrier protein domains in peptide synthetases. Biochemistry 37:1585-1595. 
Rhoads, D. M., Levings, C. S., 3rd, and Siedow, J. N. 1995. URF13, a ligand-gated, pore-forming receptor for T-toxin in the inner membrane of cms-T mitochondria. J. Bioenerg. Biomembr. 27: 437-445.

Sevim, A., Donzelli, B. G., Wu, D., Demirbag, Z., Gibson, D. M., and Turgeon, B. G. 2012. Hydrophobin genes of the entomopathogenic fungus, Metarhizium brunneum, are differentially expressed and corresponding mutants are decreased in virulence. Curr. Genet. 58: 79-92.

Tamura, K., Stecher, G., Peterson, D., Filipski, A., and Kumar, S. 2013. MEGA6: Molecular evolutionary genetics analysis version 6.0. Mol Biol. Evol. 30:2725-2729.

Turgeon, B. G., Oide, S., and Bushley, K. 2008. Creating and screening Cochliobolus heterostrophus non-ribosomal peptide synthetase mutants. Mycol. Res. 112:200-206.

Tzeng, T. H. 1990. A restriction fragment length polymorphism map of Cochliobolus heterostrophus. Ph.D. thesis. Iowa State University, Ames, IA, U.S.A.

Velázquez-Robledo, R., Contreras-Cornejo, H. A., Macias-Rodriguez, L., Hernandez-Morales, A., Aguirre, J., Casas-Flores, S., Lopez-Bucio, J., and Herrera-Estrella, A. 2011. Role of the 4-phosphopantetheinyl transferase of Trichoderma virens in secondary metabolism and induction of plant defense responses. Mol. Plant-Microbe Interact. 24:1459-1471.

Wiemann, P., Albermann, S., Niehaus, E. M., Studt, L., von Bargen, K. W., Brock, N. L., Humpf, H. U., Dickschat, J. S., and Tudzynski, B. 2012. The Sfp-type $4^{\prime}$-phosphopantetheinyl transferase Ppt1 of Fusarium fujikuroi controls development, secondary metabolism and pathogenicity. PLoS One 7:e37519.

Wolpert, T. J., Dunkle, L. D., and Ciuffetti, L. M. 2002. Host-selective toxins and avirulence determinants: What's in a name? Annu. Rev. Phytopathol. 40:251-285.
Wu, D., Oide, S., Zhang, N., Choi, M. Y., and Turgeon, B. G. 2012. ChLae1 and ChVel1 regulate T-toxin production, virulence, oxidative stress response, and development of the maize pathogen Cochliobolus heterostrophus. PLoS Pathog. 8:e1002542.

Xue, C., Wu, D., Condon, B. J., Bi, Q., Wang, W., and Turgeon, B. G. 2013. Efficient gene knockout in the maize pathogen Setosphaeria turcica using Agrobacterium tumefaciens-mediated transformation. Phytopathology 103:641-647.

Yang, G., Rose, M. S., Turgeon, B. G., and Yoder, O. C. 1996. A polyketide synthase is required for fungal virulence and production of the polyketide T-toxin. Plant Cell 8:2139-2150.

Zhang, N., Mohd Zainudin, N. A. I., Scher, K., Condon, B. J., Horwitz, B. A., and Turgeon, B. G. 2013. Iron, oxidative stress, and virulence: Roles of iron-sensitive transcription factor Sre1 and the redox sensor ChAp1 in the maize pathogen Cochliobolus heterostrophus. Mol. PlantMicrobe Interact. 26:1473-1485.

\section{AUTHOR-RECOMMENDED INTERNET RESOURCES}

ClustalW: http://www.ebi.ac.uk/tools/clustalw2

Joint Genome Institute (JGI) portals: http://genome.jgi.doe.gov/CocheC4_1/CocheC4_1.home.html

JGI MycoCosm homepage:

http://genome.jgi.doe.gov/programs/fungi/index.jsf

JGI MycoCosm databases:

http://genome.jgi.doe.gov/Cocmi1/Cocmi1.home.html http://genome.jgi.doe.gov/Cocvi1/Cocvi1.home.html

Primer3 plus software: http://www.bioinformatics.nl/cgi-bin/primer3plus/primer3plus.cgi

ProtTest web server: http://darwin.uvigo.es/software/prottest_server.html 